\title{
The role of human papillomavirus in head and neck cancer in Senegal
}

\author{
Cathy Ndiaye ${ }^{1,7^{*}}$, Laia Alemany ${ }^{2,3}$, Yankhoba Diop ${ }^{4}$, Nafissatou Ndiaye ${ }^{5}$, Marie-Joseph Diémé ${ }^{\text {, Sara Tous }}{ }^{2}$, \\ Jo Ellen Klaustermeier ${ }^{2,3}$, Maria Alejo ${ }^{2}$, Xavier Castellsaguée ${ }^{2,3}$, F Xavier Bosch ${ }^{2,6}$, Helen Trottier ${ }^{1,7}$ and \\ Silvia de Sanjosé $e^{2,3}$
}

\begin{abstract}
Background: Exploring the presence and role of human papillomavirus (HPV) in head and neck cancer (HNC) is a necessary step to evaluate the potential impact of HPV prophylactic vaccines.

Objective: To assess the prevalence and oncogenic role of HPV in HNC in Senegal.

Methods: This is a multicenter cross-sectional study. Paraffin-embedded blocks of cases diagnosed with invasive HNC between 2002 and 2010 were collected from 4 pathology laboratories in Senegal. Presence of HPV DNA was determined by PCR and DEIA, and genotyping performed with LiPA 25 . Tubulin analysis was performed to assess DNA quality. HPV DNA-positive cases were tested for p16 $6^{\mathrm{INK} 4 \mathrm{a}}$ expression.

Findings: A total of 117 cases were included in the analysis: $71 \%$ were men, mean age was 52 years old (SD \pm 18.3 ), and $96 \%$ of cases were squamous cell carcinoma. Analysis was performed on 41 oral cavity tumors, 64 laryngeal tumors, 5 oropharyngeal tumors and 7 pharyngeal tumors. Only four cases $(3.4 \% ; 95 \% \mathrm{Cl}=0.9 \%-8.5 \%)$ harbored HPV DNA. HPV types detected were HPV16, HPV35 and HPV45. However, among HPV-positive cases, none showed p16 ${ }^{\text {INK4a }}$ overexpression.
\end{abstract}

Conclusion: Our findings indicate that HPV DNA prevalence in HNC in Senegal is very low, suggesting that HPV is not a strong risk factor for these cancers. Additional larger studies are needed to confirm these findings and explore other potential risk factors specific to the region.

Keywords: Head and neck cancer, Human papillomavirus, Senegal, Sub-Saharan Africa

\section{Introduction}

Head and neck cancer (HNC) is the eighth most common cancer worldwide with approximately 650,000 new cases and 350,000 deaths reported each year [1]. In addition to alcohol and tobacco consumption, the latest evaluation on the carcinogenicity of infections and cancer by the International Agency for Research on Cancer established human papillomavirus (HPV) as a carcinogen of the oral cavity and oropharynx [2].

In sub-Saharan Africa, knowledge on the role of HPV in $\mathrm{HNC}$ is very limited. Actually, $84 \%$ of the existing

\footnotetext{
* Correspondence: cathy.ndiaye@umontreal.ca

${ }^{1}$ Department of Social and Preventive Medicine, Université de Montréal

Sainte-Justine Hospital Research Center, 3175 Côte Sainte-Catherine, Room

A-830, Montreal, QC H3T 1C5, Canada

${ }^{7}$ Sainte-Justine Hospital Research Center, Montreal, Canada

Full list of author information is available at the end of the article
}

information on HPV and HNC is derived from studies in Europe and North America [3]. The aim of our research is to provide original data on the role of HPV in invasive $\mathrm{HNC}$ in Senegal.

\section{Material and methods}

This is a cross-sectional study designed and coordinated by the Catalan Institute of Oncology in Barcelona and is part of a large international study on HPV in HNC. Four major centers in Dakar, Senegal, have provided consecutive cases diagnosed with HNC from 2002 to 2010: Centre Hospitalier Universitaire A. Le Dantec, Hôpital Principal de Dakar, Hôpital Général de Grand Yoff and the pathology laboratory at Cheikh Anta Diop University. For each specimen, after pathological confirmation of invasive diagnosis, a paraffin tissue section was treated with $250 \mu \mathrm{l}$ of freshly prepared Proteinase K solution to extract DNA.

\section{Ciomed Central}


SPF-10 polymerase chain reaction (PCR) was performed using $10 \mu \mathrm{l}$ of a 1:10 dilution of the crude DNA extract in a final reaction volume of $50 \mu \mathrm{l}$. The amplified PCR products were tested using a probe hybridization step with a cocktail of conservative probes that can recognize around 54 mucosal HPV genotypes using a microtiter plate format for the detection of HPV DNA through a DNA enzyme immunoassay (DEIA) (produced by DDL, Voorburg, the Netherlands). Optical densities (OD450) were read on a microtiter plate reader and categorized as HPV DNA negative, positive, or borderline. After PCR, $10 \mu \mathrm{l}$ of the DEIA HPV DNA positive amplimers were used to perform the reverse hybridization line probe assay $\left(\mathrm{LiPA}_{25}\right)$ (version 1: produced by DDL, Voorburg, the Netherlands). The $\mathrm{LiPA}_{25}$ detects 25 high-risk and low-risk HPV types $(6,11,16,18,31,33,34,35,39,40,42,43,44,45,51,52$, $53,54,56,58,59,66,68,70$, and 74). Additionally, amplification of the human tubulin gene was performed to determine DNA quality of DEIA negative samples. In HPV DNA-positive samples, p16 ${ }^{\mathrm{INK} 4 \mathrm{a}}$ overexpression was evaluated using CINtec histology kit (clone E6H4, mtm Laboratories, Heidelberg, Germany) in order to verify the potential causal role of HPV in positive cases. Overall HPV detection percentages and 95\% confidence intervals (95\% CI) were estimated. Data analyses were performed with STATA 11.0. Ethical approval was obtained from the Ministry of Health of Senegal.

\section{Findings}

Figure 1 displays the algorithm of sample selection for analysis. The final number of cases included in the study was 117: 41 oral cavity tumors, 64 laryngeal tumors (including 25 tumors whose site could not be discerned between hypopharynx and larynx), 5 oropharyngeal tumors and 7 pharyngeal tumors. Description of the cases is presented in Table 1. In this study, $70.9 \%$ of cases were men and mean age was 52 years old (SD \pm 18.3 ). Squamous cell carcinoma (SCC) represented $95.7 \%$ of cases.

The overall HPV prevalence was 3.4\%; 95\% CI $=0.9 \%$ $8.5 \%$. Table 2 shows the number of cases per subsite, the distribution of HPV genotypes and results for $\mathrm{p} 16^{\mathrm{INK} 4 \mathrm{a}}$ expression. HPV DNA was detected in 4 carcinomas: one gingival SCC (HPV35) and three laryngeal SCC (2 HPV45 and 1 HPV16). However, none of these cases showed p16 ${ }^{\text {INK4a }}$ overexpression: 3 cases showed no $\mathrm{p} 16^{\mathrm{INK} 4 \mathrm{a}}$ staining and one HPV45 laryngeal cancer case showed focal staining of less than $25 \%$ of cells with low-moderate intensity.

\section{Discussion}

To our knowledge, this is the first study to explore the presence of viral DNA and cellular protein expression in head and neck tumors in West Africa. HPV DNA was detected in $3.4 \%$ (95\% CI $=0.9 \%-8.5 \%)$ of studied cases but further analyses testing for $\mathrm{p} 16^{\mathrm{INK} 4 \mathrm{a}}$ expression suggested that HPV was not involved in the oncogenic process of the tumors. Expression of $\mathrm{p} 16^{\mathrm{INK4a}}$ is strongly seen in HPVassociated tumors but nearly absent in HPV-negative carcinomas [4] and increases in cases where HPV is oncogenically involved due to the interaction of the viral oncoprotein E7 with pRb [5].

Similar low HPV prevalences have been reported in the African-American community in the USA. In a prospective

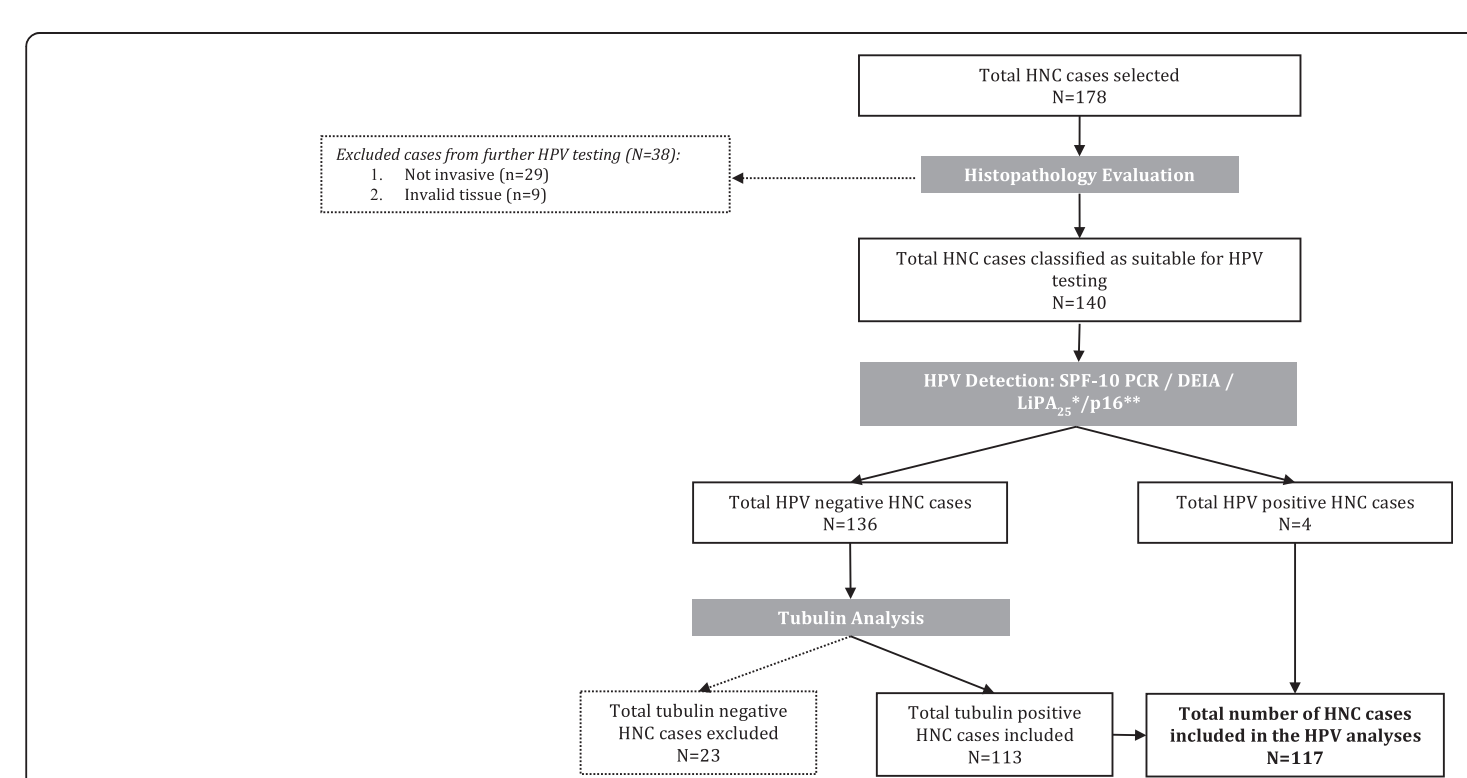

HNC: Invasive Head and Neck Cancer; ${ }^{*} L i P A_{25}$ performed only in DEIA positive cases; ${ }^{* *} p 16$ performed only in DEIA positive cases

Figure 1 Algorithm of head and neck cancer cases included in the study. 
Table 1 HPV DNA detection in head and neck cancer cases in Senegal by subjects' characteristics

\begin{tabular}{|c|c|c|c|c|}
\hline \multirow[t]{2}{*}{ Variables } & \multicolumn{2}{|c|}{$\begin{array}{c}\text { Cases tested for } \\
\text { HPV }\end{array}$} & \multicolumn{2}{|c|}{$\begin{array}{l}\text { HPV positive } \\
\text { cases }\end{array}$} \\
\hline & $\mathrm{N}$ & $\%$ & $\mathbf{N}$ & $\%(95 \% \mathrm{Cl})$ \\
\hline \multicolumn{5}{|l|}{ Gender } \\
\hline Male & 83 & 70.9 & 1 & $1.2(0.0-6.5)$ \\
\hline Female & 34 & 29.1 & 3 & $8.8(1.9-23.4)$ \\
\hline \multicolumn{5}{|l|}{ Age at diagnosis (in years) } \\
\hline$\leq 39$ & 28 & 23.9 & 1 & $3.6(0.0-18.3)$ \\
\hline $40-49$ & 16 & 13.7 & 1 & $6.2(0.2-30.2)$ \\
\hline 50-59 & 19 & 16.2 & 0 & $0.0(0.0-17.6)^{b}$ \\
\hline$\geq 60$ & 49 & 41.9 & 2 & $4.1(0.5-14.0)$ \\
\hline Missing & 5 & 4.3 & 0 & $0.0(0.0-52.2)^{b}$ \\
\hline \multicolumn{5}{|l|}{ Period of diagnosis } \\
\hline $2002-2008$ & 53 & 45.3 & 3 & $5.7(1.2-15.7)$ \\
\hline $2009-2010$ & 64 & 54.7 & 1 & $1.6(0.0-8.4)$ \\
\hline \multicolumn{5}{|l|}{ Histological type } \\
\hline Squamous cell carcinoma & 112 & 95.7 & 4 & $3.6(1.0-8.9)$ \\
\hline Adenocarcinoma & 1 & 0.9 & 0 & $0.0(0.0-97.5)^{b}$ \\
\hline Other diagnoses ${ }^{\mathrm{a}}$ & 4 & 3.4 & 0 & $0.0(0.0-60.2)^{b}$ \\
\hline Total & 117 & 100 & 4 & $3.4(0.9-8.5)$ \\
\hline
\end{tabular}

a Other diagnoses include 2 small cell neuroendocrine carcinomas and 2 adenoid cystic carcinomas.

${ }^{b}$ One-sided, $97.5 \%$ confidence interval.

study conducted by Settle et al. [6], overall HPV positivity was $4 \%$ in black patients diagnosed with oropharyngeal cancer versus $34 \%$ in white patients. Weinberger et al. [7] found $0 \% \mathrm{HPV}$-active HNC in black patients compared to $21 \%$ in white patients after immunohistochemical testing with $\mathrm{p} 16^{\mathrm{INK} 4 \mathrm{a}}$. Both studies agree on significant ethnic and biological disparities in HPV prevalence, after adjusting for clinical and sociodemographic characteristics, and support the validity of our study. Further studies are needed to elucidate the mechanism of HPV clearance in AfricanAmerican and African populations, which share common ancestral origins.

These findings are very different from what has been reported previously in other regions of the world. In a systematic review by Kreimer et al. [3] compiling data on 60 studies focusing on HNSCC, HPV DNA was detected overall in $26 \%$ of cases. Reported site-specific HPV prevalence was $23.5 \%$ (95\% CI $=21.9-25.1 \%)$ in oral SCC, $35.6 \%$ $(95 \% \mathrm{CI}=32.6-38.7 \%)$ in oropharyngeal SCC and $24.0 \%$ $(95 \% \mathrm{CI}=21.8-26.3 \%)$ in laryngeal SCC [3]. The highest detection rates were found in Asia, followed by the USA and Nordic countries [3].

Low HPV prevalence in invasive HNC in Senegal suggest that other established risk factors such as alcohol and tobacco consumption may play a more significant etiological role than HPV infection in HNC. However, the prevalence of tobacco use in Senegal is relatively low with estimates of $19.9 \%$ in men and $1.3 \%$ in women [8]. Alcohol consumption is also negligible, especially in women, since Senegal is a predominantly Muslim country with $95 \%$ of the population practicing this religion. Thus, the magnitude of the implication of these two classical risk factors in the development of $\mathrm{HNC}$ is probably small given the social norms. Therefore, we hypothesize that environmental factors and eating habits may contribute more importantly to the development of HNC.

For example, indoor air pollution causes 6,300 deaths each year in Senegal due to daily exposure to smoke from open burning of wood and charcoal in homes [9]. More than $80 \%$ of the households use either wood or charcoal as cooking fuels in peri-urban and rural Senegal. Moreover, burning incense to deodorize and heat the indoor is a widely practiced cultural habit. The aforementioned are potential risk factors for laryngeal and nasopharyngeal cancers as they expose individuals to smoke and dangerous emissions of particles such as $\mathrm{CO}_{2}$ and $\mathrm{CO}$ [9]. According to the $\mathrm{WHO}, 3.7 \%$ of the burden of disease in developing countries can be attributed to indoor air pollution [9].

Another potential risk factor could be the consumption of "ataya", a strong and bitter hot tea comparable to "yerba mate" in South America, which has been associated with an increased risk of developing cancer of the oral cavity, larynx and esophagus [10]. On average, at least three rounds of "ataya" are served twice a day in Senegal. The fact that this tea is drank at very hot temperature and consumed with slurps can contribute to an increased risk of cancer.

Poor oral hygiene is another potential risk factor that has been documented [11] and could play a non-negligible role in Senegal. A study in 330 Senegalese university students has shown poor dental health and the need to improve prevention programs [12]. This study was conducted in an educated cohort, which suggests that dental issues may be worse in uneducated, low socio-economic populations with limited access to dental care. Moreover, chewing of kola nuts (Cola acuminate) has also been reported to increase carcinogenesis potential of tobacco in smokers in Nigeria by promoting palatal mucosa keratinization [13]. Consumption of kola nuts is also widespread in Senegal.

Occupational exposure such as jobs in the construction, metal, textile, ceramic, logging, and food industries has been associated with the development of laryngeal cancer [14]. In Senegal, protective masks and safety rules are not applied, as workplace safety regulations are not reinforced mainly due to the fact that the informal sector provides most of the jobs. This reality puts workers in a difficult predicament whereby they expose themselves to hazardous materials.

Our study has some methodological limitations. At sample collection stage, some cases were identified eligible for the study but corresponding blocks were not found as they 
Table 2 HPV DNA, HPV types and p16 ${ }^{\text {INK4a }}$ detection in HPV positive cases by head and neck cancer sites and subsites

\begin{tabular}{|c|c|c|c|c|c|c|}
\hline \multirow[t]{2}{*}{ HNC sites and subsites } & \multicolumn{2}{|c|}{ Cases tested for HPV } & \multicolumn{2}{|c|}{ HPV DNA positive } & \multirow[t]{2}{*}{ HPV type } & \multirow[t]{2}{*}{ p16 ${ }^{\text {INK4a }}$ overexpression } \\
\hline & $\mathrm{N}$ & $\%$ & $\mathrm{~N}$ & $\%(95 \% \mathrm{Cl})$ & & \\
\hline \multicolumn{7}{|l|}{ Oral cavity } \\
\hline Lip & 4 & 3.4 & 0 & 0.0 & & \\
\hline Gingiva & 5 & 4.3 & 1 & $20.0(0.5-71.6)$ & HPV35 $(\mathrm{N}=1)$ & Negative \\
\hline Floor of the mouth & 1 & 0.9 & 0 & 0.0 & & \\
\hline Tongue & 25 & 21.4 & 0 & 0.0 & & \\
\hline Hard palate & 3 & 2.6 & 0 & 0.0 & & \\
\hline Palate unspecified & 2 & 1.7 & 0 & 0.0 & & \\
\hline Oral cavity unspecified & 1 & 0.9 & 0 & 0.0 & & \\
\hline \multicolumn{7}{|l|}{ Larynx } \\
\hline Epiglottis & 2 & 1.7 & 0 & 0.0 & & \\
\hline \multirow[t]{2}{*}{ Vocal cord } & 2 & 1.7 & 0 & 0.0 & & \\
\hline & & & & & HPV45 $(\mathrm{N}=2)$ & \\
\hline Larynx unspecified & 35 & 29.9 & 3 & $8.6(1.8-23.1)$ & HPV16 $(\mathrm{N}=1)$ & Negative \\
\hline Hypopharynx or larynx & 25 & 21.4 & 0 & 0.0 & & \\
\hline \multicolumn{7}{|l|}{ Oropharynx } \\
\hline Tonsil & 1 & 0.9 & 0 & 0.0 & & \\
\hline Oropharynx unspecified & 4 & 3.4 & 0 & 0.0 & & \\
\hline \multicolumn{7}{|l|}{ Pharynx } \\
\hline Pharynx unspecified & 1 & 0.9 & 0 & 0.0 & & \\
\hline Nasopharynx & 6 & 5.1 & 0 & 0,0 & & \\
\hline Total & 117 & 100.0 & 4 & $3.4(0.9-8.5)$ & & \\
\hline
\end{tabular}

HNC: Head and neck cancer.

were sent to laboratories abroad for histopathological evaluation. Additionally, several archival records were lost in one of the main laboratories due to a fire. However, these issues affected all cases regardless of patient characteristics or diagnosis. Another major limitation is the lack of individual data on risk factors: no information on patients besides their gender, age and pathological information were available in the registries. Finally, the small sample size $(n=5)$ for oropharyngeal tumors may have affected our positivity rate. It is recognized that the highest associations of HPV in $\mathrm{HNC}$ have been shown in the oropharynx, particularly in the tonsils, with a positivity of $57 \%$ to $82 \%$ compared to $0.8 \%$ to $9 \%$ in other anatomic sites [15].

Our study has several strengths comprising the combined use of highly sensitive assays for HPV DNA detection and a marker of HPV related transforming process such as p $16^{\mathrm{INK} 4 \mathrm{a}}$ expression. Additionally, we evaluated the quality of our specimens by means of cellular tubulin detection and subsequently excluded the HPV DNA negative and tubulin negative cases from the statistical analyses. Lastly, all of the study cases were selected from the main anatomy and pathology laboratories in Senegal. Thus, our cohort is representative of the target population as the vast majority of patients are diagnosed in participant centers.

\section{Conclusion}

In Senegal, HPV prevalence in HNC is very infrequent and $\mathrm{HPV}$ infection is not associated with carcinogenesis. Therefore, HPV prophylactic vaccines would not have any impact on HNC incidence. Our findings need to be further validated with supplementary studies that include larger case series and the assessment of region-specific risk factors. Additional data will allow to close the gap of knowledge between Western countries and the sub-Saharan African region and to assist health authorities in implementing public health strategies.

\section{Competing interests}

HT served as a consultant and on advisory boards and received speaker fees and travel assistance from Merck-Frosst Canada and Glaxo Smith Kline Pharmaceuticals, Belgium. LA occasionally received travel grants to attend conferences granted by Merck and Sanofi Pasteur MSD. XC received trave grants for scientific meetings and honorarium for consultancy occasionally granted by GlaxoSmithKline, Merck, Sanofi Pasteur MSD. XB received travel grants to conferences/symposia/meetings and honorarium occasionally granted by GlaxoSmithKline, Merck, Sanofi Pasteur MSD, Roche or Qiagen. SS received travel grants to conferences/symposia/meetings occasionally granted by GlaxoSmithKline, Sanofi Pasteur MSD or Qiagen. Other co-authors have no potential conflict of interest to declare.

\section{Authors' contributions}

CN collected data, performed data analysis and drafted the manuscript. SJ, $X C, F X B$ and LA initiated and designed the study. LA, HT and SJ guided data 
analysis, interpreted data and edited the paper. $\mathrm{XC}$ and FXB made substantial contributions to the manuscript and contributed to data interpretation. NN, YD and MJD interpreted data and edited the paper. JEK performed the laboratory tests and MA the histopathological evaluation. ST managed and cleaned the database. All authors read and approved the final manuscript.

\section{Acknowledgements}

We are grateful to Dr. Magib Gaye and Dr. Ibrahima Thiam for their contribution to data collection.

\section{Funding sources}

The study was partially supported by: Spanish public grants from the Instituto de Salud Carlos III (grants FIS PI081535, PI11 02104, RCESP C03/09, RTICESP C03/10, RTIC RD06/0020/0095 and CIBERESP), the Agència de Gestió d'Ajuts Universitaris i de Recerca (AGAUR 2005SGR 00695), and Sanofi Pasteur MSD \& Merck \& Co, Inc., who had no role in the data collection, analysis or interpretation of the results. CN received a training scholarship from Fonds de Recherche en Santé du Québec and was also supported by an HPV infection and associated diseases team grant from the Canadian Institutes of Health Research (CIHR) held by HT.

\section{Role of funding sources}

The sponsors did not have any role in the study design, collection, analysis or interpretation of the data.

\section{Author details}

'Department of Social and Preventive Medicine, Université de Montréal Sainte-Justine Hospital Research Center, 3175 Côte Sainte-Catherine, Room A-830, Montreal, QC H3T 1C5, Canada. ${ }^{2}$ Unit of Infections and Cancer, Institut Català d'Oncologia, Barcelona, Spain. ${ }^{3} \mathrm{C}$ BBER Epidemiología y Salud Pública, CIBERESP, Barcelona, Spain. ${ }^{4}$ Hôpital Principal de Dakar, Dakar, Senegal. ${ }^{5}$ Université Cheikh Anta Diop, Dakar, Senegal. ${ }^{6}$ Red Temàtica de Investigaciòn Cooperativa en Càncer, RTICC, Barcelona, Spain. ${ }^{7}$ Sainte-Justine Hospital Research Center, Montreal, Canada.

\section{Received: 15 October 2012 Accepted: 12 April 2013}

Published: 17 April 2013

\section{References}

1. Ferlay J, Shin H-R, Bray F, Forman D, Mathers C, Parkin DM: Estimates of worldwide burden of cancer in 2008: GLOBOCAN 2008. Int J Cancer 2010, 127(12):2893-2917.

2. IARC: Monographs on the evaluation of carcinogenic risks to humans, vol. 100. A review of human carcinogens. Part B: Biological agents. Lyon, France: International Agency for Research on Cancer; 2010.

3. Kreimer AR, Clifford GM, Boyle P, Franceschi S: Human papillomavirus types in head and neck squamous cell carcinomas worldwide: a systematic review. Cancer Epidemiol BiomarkersPrev 2005, 14(2):467-475.

4. Jung AC, Briolat J, Millon R, de Reyniès A, Rickman D, Thomas E, et al: Biological and clinical relevance of transcriptionally active human papillomavirus (HPV) infection in oropharynx squamous cell carcinoma. Int J Cancer 2010, 126(8):1882-1894.

5. Smeets SJ, Hesselink AT, Speel E-JM, Haesevoets A, Snijders PJF, Pawlita M, et al: A novel algorithm for reliable detection of human papillomavirus in paraffin embedded head and neck cancer specimen. Int J Cancer 2007, 121(11):2465-2472.

6. Settle K, Posner MR, Schumaker LM, Tan M, Suntharalingam M, Goloubeva O, et al: Racial Survival Disparity in Head and Neck Cancer Results from Low Prevalence of Human Papillomavirus Infection in Black Oropharyngeal Cancer Patients. Cancer Prev Res 2009, 2(9):776-781.

7. Weinberger PM, Merkley MA, Khichi SS, Lee JR, Psyrri A, Jackson LL, et al: Human Papillomavirus-Active Head and Neck Cancer and Ethnic Health Disparities. Laryngoscope 2010, 20:1531.

8. Institut Català d'Oncologia, World Health Organization, Information Centre on HPV and Cervical Cancer (HPV Information Centre: Human Papillomavirus and Related Cancers in Senegal. Summary Report Update. 2010. Available at www.who.int/hpvcentre.

9. World Health Organization: Indoor Air Pollution, Health and the Burden of Disease. 2010. http://www.who.int/indoorair/en/.
10. Dasanayake AP, Silverman AJ, Warnakulasuriya S: Maté drinking and oral and oro-pharyngeal cancer: a systematic review and meta-analysis. Oral Oncol 2010, 46(2):82-86.

11. Guha N, Boffetta P, WünschFilho V, ElufNeto J, Shangina O, Zaridze D, et a: Oral health and risk of squamous cell carcinoma of the head and neck and esophagus: results of two multicentric case-control studies. Am J Epidemiol 2007, 166(10):1159-1173.

12. Faye D, Cisse D, Mbodj EB, Lo CMM: Epidemiologic study of dental caries among students on the campus of the University of Dakar. Odontostomatol Trop 2007, 30(119):29-36.

13. da Lilly-Tariah $\mathrm{OB}$, Somefun AO, Adeyemo WL: Current evidence on the burden of head and neck cancers in Nigeria. Head Neck Oncol 2009, 1:14

14. Paget-Bailly S, Cyr D, Luce D: Occupational exposures and cancer of the larynx-systematic review and meta-analysis. J Occup Environ Med 2012, 54(1):71-84.

15. Snow AN, Laudadio J: Human papillomavirus detection in head and neck squamous cell carcinomas. Adv Anat Pathol 2010, 17:394-403.

doi:10.1186/1750-9378-8-14

Cite this article as: Ndiaye et al:: The role of human papillomavirus in head and neck cancer in Senegal. Infectious Agents and Cancer 2013 8:14.

\section{Submit your next manuscript to BioMed Central and take full advantage of:}

- Convenient online submission

- Thorough peer review

- No space constraints or color figure charges

- Immediate publication on acceptance

- Inclusion in PubMed, CAS, Scopus and Google Scholar

- Research which is freely available for redistribution

Submit your manuscript at www.biomedcentral.com/submit
C Biomed Central 